( $\mathrm{Mg}, \mathrm{Ca}, \mathrm{Sr}, \mathrm{Ba})$ and the $\mathrm{HM}(\mathrm{Cu}, \mathrm{Zn}, \mathrm{Pb})$ ions.The results are in good agreement with that of Rogozhina, who determined aluminium at $\mathrm{pH} \mathbf{1 0 . 5}$ by back titrating excess EDTA with $\mathrm{ZnSO}_{4}$ using chromogen dark blue.

Khalifa and Ismail [2] found that in the analysis of aluminium mixtures, the presence of any stable metal-ED'TA complex favours the accuracy of the determination of aluminium and prevents fading of the potential at the end point.

Results of analyses of Ti mixtures (in about the same amounts as in the case of $\mathrm{Al}$ ) were also in most cases fairly accurate indicating the reliability of the adopted procedure for such an analysis.

The potential breaks are sharp enough to permit accurately the determination of the end points within $0.02 \mathrm{ml}$ of 0.05 or $0.01 \mathrm{M}$ titrant. The breaks lying in the immediate vicinity of the three end points mentioned above are of good order of magnitude amounting in average to 70,130 and $170 \mathrm{mV} / 0.1 \mathrm{ml}$ of $0.05 \mathrm{M}$ $\mathrm{Hg}$ (II) with Al mixtures and 60,120 and $100 \mathrm{mV} /$ $0.1 \mathrm{ml}$ of $0.05 \mathrm{M}$ titrant with titanium mixtures.

The analysis of the above mentioned mixtures was also performed using a platinum electrode instead of

\section{Indirect Potentiometric Determination of Bismuth and Orthophosphate}

Indirekte potentiometrische Bestimmung von Wismut und Orthophosphat

Best. von Wismut und Phosphat; Potentiometrische Titration; ÄDTA/Hg

H. Khalifa, M. M. Khater, and M. A. Zayed

Chem. Dept., Fac. of Science, Cairo University, Giza, Egypt

Received February 13, 1973; revised May 21, 1973

A procedure has been worked out for the determination of bismuth and orthophosphate employing the back-titration of unconsumed EDTA with mercury(II) in hexamine buffered medium, using silver amalgam as indicator electrode coupled with saturated calomel electrode. The potentiometric end-point determination ensures higher accuracy than visual the silver amalgam electrode. The potential breaks detecting the end points are of lower magnitude than those obtained with the silver amalgam electrode ranging from 40 to $144 \mathrm{mV} / 0.1 \mathrm{ml}$ titrant, which are still sharp enough to permit requisite accuracy.

The importance of the present work stems from the fact that components of the analysed mixtures are constituents of many useful alloys.

\section{References}

1. Welcher, F. J.: The Analytical Uses of Ethylene Diamine Tetraacetic Acid, Princeton, N. J.: D. von Nostrand Co. 1958.

2. Khalifa, H., Ismail, F. A. : Microchem. J. 14, 12-21 (1969).

3. Khalifa, H., Ismail, F. A.: Michrochem. J. 14, $353-360$ (1969).

4. Khalifa, H., Khater, M. M.: J. Chem. U.A.R. 10, No. 2, 123-129 (1967).

5. Vogel, A. I.: Quantitative Inorganic Analysis, 3rd Edit. New York: Longmans Green, 1962.

Prof. Dr. H. Khalifa

Faculty of Science

Cairo University

Giza, Egypt methods. With 0.1 to $104 \mathrm{mg}$ of $\mathrm{Bi}$ the percentage error was $0.3 \%$ at most, in the case of 0.5 to $50 \mathrm{mg}$ of phosphate it was $0.3 \%$ also.

Determination of Bismuth. To $2 \mathrm{ml}$ of sample solution add $4 \mathrm{ml}$ of $0.1 \mathrm{M}$ EDTA solution, $8 \mathrm{ml}$ of $10 \%$ hexamine solution and enough $0.4 \mathrm{M} \mathrm{HNO}_{3}$ or $0.5 \mathrm{M} \mathrm{NaOH}$ to adjust the $\mathrm{pH}$ to $8-9$. Make with water up to $25 \mathrm{ml}$ and titrate unconsumed EDTA with $0.1 \mathrm{M} \mathrm{Hg}$ (II) nitrate solution using silver amalgam as indicator electrode.

Determination of Phosphate. To $\mathbf{1 - 5} \mathrm{ml}$ of boiling sample solution (0.1 M in $\mathrm{HNO}_{3}$ ), add an excess of standard $0.1 \mathrm{M}$ Bi solution $(3-8 \mathrm{ml})$ with constant stirring, heat for 10 to 15 min on a water bath to not less than $10 \mathrm{ml}$, filter from $\mathrm{Bi}$ phosphate, wash the precipitate with $5 \mathrm{ml}$ portions of hot $0.4 \mathrm{M} \mathrm{HNO}_{3}$, combine with the filtrate, add $5-10 \mathrm{ml}$ of EDTA solution, $8 \mathrm{ml}$ of hexamine solution, adjust to $\mathrm{pH} 8-9$ and back-titrate unconsumed. EDTA with standard $\mathrm{Hg}(\mathrm{II})$ solution as above. Calculate Bi equivalent to phosphate.

Prof. Dr. H. Khalifa

Chem. Dept., Fac. of Science

University of Cairo

Giza, Egypt 